\title{
Live donor kidney transplantation pearls: a practical review
}

\begin{abstract}
Living donation is "a gift of extraordinary value". The use of living donors for renal transplantation was critical for the early development of the field and preceded the use of cadaveric donors. Most donors are related genetically to the recipient, but there are an increasing percentage of cases, where donors are genetically unrelated like spouses, friends, or other emotionally related individuals. Ethical guidelines mandate that the living donors should not be coerced without any evidence of financial profit for the donor. Living donation has been associated with a higher success rate than that seen with cadaveric donation.
\end{abstract}

Conclusion: In view of higher demand for transplantation and the lack of a parallel increase in the number of available cadaveric organs, living donation is important solution for patients to avoid long times on waiting list, and occasionally, even the need of dialysis so, much efforts are needed to encourage living donation rates.

Keywords: living donor, kidney transplantation, graft survival
Volume 5 Issue 4 - 2017

\author{
Yasser Elsayed Matter, Tarek Medhat Abbas, \\ Ayman Maher Nagib, Mohammed Ashraf \\ Fouda, Mohamed Hamed Abbas, Ayman Fathi \\ Refaie, Ahmed Abdelfattah Denewar, Ahmed \\ Yahia Elmowafy, Hussein Attia Sheashaa \\ Department of dialysis and transplantation, The Urology- \\ Nephrology Center, Mansoura University, Egypt
}

\begin{abstract}
Correspondence: Yasser Elsayed Matter, Department of dialysis and transplantation, Urology \& Nephrology Center, Mansoura University, Mansoura, Egypt, Fax 20502263717, Email yassermatter86@gmail.com
\end{abstract}

Received: September 28, 2017 | Published: October 20, 2017

\section{Introduction}

Renal transplantation is currently the best method for management of patients with end-stage renal disease (ESRD). Kidney transplantation offers the patients a higher quality of life with less consumption of health care resources compared with dialysis. ${ }^{1}$ Renal failure is a common health problem with rapid increase in the number of patients. The shortage of donors is an obstacle that limits kidney transplantation as a treatment option. Living donation is gaining popularity especially with the superior outcomes of living donor's kidney transplantations as compared to the cadaveric donors. The rates of living-donor kidney transplantation steadily rise in most regions of the world. ${ }^{2}$ It is considered the best choice for most patients. ${ }^{3}$ Therefore, much effort has been made to increase the supply of living donors. The first successful kidney transplant program was carried out at Peter Bent Brigham hospital in Boston, in 1954, Dr. Joseph Murray performed the first successful kidney transplant between identical twin. ${ }^{4}$ Cross skin grafting was performed between the 2 brothers and skin grafts survived for weeks establishing "genetic identity". Thirty days later, kidney transplantation was performed. During the next four years, the team performed seven more transplants. The patient died after eight years due to development of recurrent glomerulonephritis in the transplanted kidney.

\section{Contraindications for renal transplantation}

Many centers now accept patients who were previously excluded from transplantation, such as those with human immunodeficiency virus (HIV) infection, obesity, and diabetes. This is because of the availability of newer treatment options for some conditions and a greater understanding of the impact of these conditions on patient and graft survival along with changing societal attitudes regarding equality of access to transplantation. Some absolute contraindications to transplantation are listed in Table $1 .{ }^{6}$ The application of guidelines for transplant suitability may be relatively straightforward for patients with a single comorbidity; meanwhile it is not as simple for those with multiple medical conditions. It is important to determine the suitability of such patients which requires team work with input from specialists in a variety of medical and surgical disciplines along with allied health professionals. The final decision needs to be a joint one between clinician and patient after full and open discussion of the likely risks and benefits followed by regular reassessment of suitability. ${ }^{7,8}$

\section{Types of living donors}

Living donors are classified into four main categories; the first is the genetically related donors such as the parents or a child of the recipient or from a haploidentical sibling. The second category includes emotionally related donors as spouses and friends. The third group includes altruistic donors. The last one includes a live-donor paired exchange. According to the OPTN/SRTR 2015 Annual Data Report, 5626 living donor transplants were performed, slightly up from 5539 in 2014 but well below the peak of 6647 in 2004. This decline appears to be due to a decrease in related kidney donations (Figure 1). ${ }^{9}$ Based on these facts, we need many efforts to enhance living donation. The adjusted 5-years allograft survival shows no statistically significant different between kidney transplant recipients who received their allografts from unrelated or related donors. ${ }^{10,11}$

Moreover, the outcome of a kidney transplant performed from a completely mismatched donor was not different from that from a haploidentical match. ${ }^{12,13} \mathrm{~A}$ better outcome is provided only by an HLA identical kidney. ${ }^{12}$ Use of child-to-parent (CTP) kidney donation may be limited because of ethical concerns as well as doubts about its effectiveness. In a study that used the United Network for Organ Sharing database to examine the effectiveness of CTP kidney donation compared with other types of living-related (LD) kidney donation and to cadaveric kidney donation. Data from 56873 kidney transplants performed between 1988 and 1998 showed significantly greater transplant and patient survival for CTP kidney transplants compared with cadaveric kidney transplants. The average gain in kidney transplant half-life is 3.6 years for a CTP compared with a cadaveric kidney transplant, and it is estimated that this gain for the recipient far outweighs the 1 in 3000 risk of death to the donor associated with kidney donation. This study concluded that CTP kidney donation should not be discouraged, and represents a useful source of transplantable kidneys..$^{14}$ 
Table I Contraindications to renal transplantation

Current Absolute Contraindications to Transplantation
Active sepsis
Current uncontrolled malignant disease
Uncontrolled psychosis
Active drug dependence
Any medical condition with a severely shortened life expectancy (<I-2 years)
Positive T cell CDC crossmatch
Previous Contraindications to Transplantation*
HIV infection
Hepatitis B and C
Obesity
Mood disorders
Age above 60 years
Previous malignant disease
Blood group incompatibility

CDC, complement dependent cytotoxicity

*These conditions are now acceptable under certain circumstances.

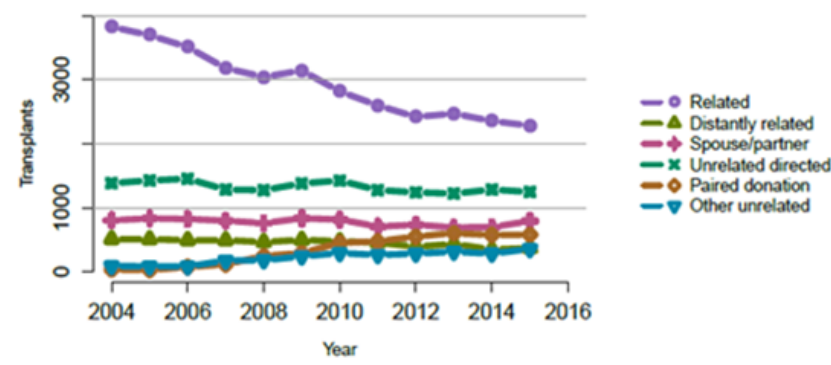

Figure I Kidney transplants from living donors by donor relation.As reported on the OPTN Living Donor Registration Form.

There is a category of living donors called "altruistic donors" or non-directed donors or 'Good Samaritan Donors'. This group donate their kidney to a completely unknown recipient, whom the donor might never meet. They represent about $1.5 \%$ of all living donors in the USA as of January 2009. The non-directed donors play an important role in living donor exchange programs and kidney paired donation (KPD). The evaluation process of this group of donors has a strong emphasis on the psychosocial aspects of the donation. Every effort is done to explore any false perceptions or covert depression. Non-directed donors have a great risk for depression or regret being not able to enjoy the positive psychological gain from seeing the recipient benefit from their altruism. ${ }^{13,15}$ Patients within compatible donors due to different $\mathrm{ABO}$ groups or positive cross-match can still have benefits from living donation through KPD. A simple "two-way" exchange, or swap, can be arranged between two incompatible pairs or a more complicated combination can be achieved using many pairs in many different hospitals. Such a large exchange is often initiated by a non-directed donor. This concept of KPD was first suggested by Felix Rapaport in 1986 and in 1991.The first kidney exchange was performed in South Korea. The next year, the first KPD transplants were performed in the USA in 2000. As of the third quarter of 2010, over 1000 KPD transplants have been performed in the USA. ${ }^{15,16}$ In Europe, several countries are running independent KPD programs, with the Dutch program being the most prominent ${ }^{17}$ and the Netherlands was the first to launch a nationwide KPD program in $2004 .{ }^{18}$ Recently, there is cross-border living donor kidney exchange between Czech Republic and Austria with short term promising results in view of immediate graft function and no signs of rejection (serum creatinine at 3 months: $84 \mathrm{mmol} / \mathrm{L}$ in the Austrian and $106 \mathrm{mmol} / \mathrm{L}$ in the Czech recipient). ${ }^{19}$

\section{Advantages of living donor transplantation}

Living donor transplantation is a preferred strategy by many centers around the world. The cause for this is the many advantages offered through living donation as compared to deceased-donor transplantation. Living donation provides a better patient and allograft survival especially when transplantation is performed before the onset of dialysis..$^{20,21}$ Despite the improved short term survival, graft survival half-lives have increased only very little, but are almost two-fold higher in recipients of living donors than those in patients receiving a transplant from a deceased donor (10 years for deceased donors versus 20years for living donors). ${ }^{22}$ Live kidney donation has also been fostered by the technical advance of laparoscopic nephrectomy and immunologic maneuvers that can overcome biologic obstacles such as HLA disparity and ABO or cross-match incompatibility. The elective nature of the surgery allows a complete medical evaluation of both recipient and donor, and the transplant can be scheduled when both are in optimal condition. The donor's kidney function can be evaluated thoroughly to ensure that both kidneys are healthy. The kidney incurs minimal ischemic damage because the donor and recipient surgeries are scheduled together. Early graft dysfunction is rarely observed in living donor transplants. ${ }^{23}$

The more uniform healthy condition of living donor kidneys compared with cadaver kidneys has been cited as one reason for their superior graft survival. ${ }^{24}$ Preemptive transplantation is possible, sparing the morbidity of chronic dialysis, as transplantation before dialysis offers cost and survival benefits for the patient. ${ }^{25}$ If the donor lives with the patient, like a spouse, compliance with medications and clinic visits should be better. ${ }^{26}$ Living donation was assessed to be free of progressive renal dysfunction or increased incidence of proteinuria. Thus, the published evidence indicates that there is little long-term medical risk to a healthy donor after unilateral nephrectomy. However, the profile of the donor has changed to include those with isolated medical abnormalities such as hypertension, an increased body mass index (BMI), dyslipidemia, and stone disease. ${ }^{27}$

Amsterdam forum participants agreed that before donation, the live kidney donor must receive a complete medical and psychosocial evaluation, receive appropriate informed consent, and be capable of understanding of the information presented in that process to make a voluntary decision. Recently, Muzaale and colleagues reported a higher risk of developing ESRD among kidney donors than among healthy non-donors. ${ }^{28}$ Previous studies had shown no significant effect of kidney donation on the risk of developing ESRD..$^{29,30}$. The study by Muzaale et al..$^{28}$ has received considerable criticism regards to the methodology used and limitations of the control groups, such as disparities between the decades in which the control and donor population data were extracted. The relative and absolute risks of ESRD should be carefully explained when counseling individuals about live kidney donation. The transplant community, however, should be urged to rapidly resolve issues pertaining to health and life insurance coverage and medical follow-up of kidney donors. ${ }^{31}$

\section{Contraindications of live donation}

The minimum absolute exclusions for live donation as defined by Organ Procurement and Transplant Network (OPTN) include those younger than 18years and mental inability to make an informed decision, uncontrolled hypertension, HIV infection, diabetes mellitus, active or incompletely treated cancer, evidence of acute symptomatic infection, high suspicion of donor coercion, high suspicion of illegal financial exchange between donor and recipient and psychiatric conditions that require treatment before donation. There is substantial 
Table Continued...

variability in the criteria used to exclude potential living donors. Generally accepted absolute contraindications include the presence of one or more of some clinical findings. ${ }^{13,32-34}$

These include proteinuria and/or haematuria, impaired renal function (defined as GFR $<80 \mathrm{~mL} / \mathrm{min} / 1.73 \mathrm{~m}^{2}$ ), markedly abnormal urologic and renal vascular abnormalities, any chronic, active viral infection (human T-lymphotropic virus.HTLV HBV and HCV), history of malignancy, chronic illness, particularly pulmonary, liver, autoimmune, neurologic, or cardiac disease, clinically significant hypertension, nephrocalcinosis, bilateral kidney stones, or recurrent nephrolithiasis, active substance abuse, pregnancy and disorders requiring anticoagulation..$^{35}$ The following are some relative contraindications to living kidney donation. These include active peptic ulcer disease, history of sickle cell trait, history of nephrolithiasis, urological abnormalities, morbid obesity (most commonly defined as BMI >35), strong family history of diabetes mellitus or hypertension, family history of renal cell cancer and ABO or HLA incompatibility which may allow for desensitization..$^{27,36}$

\section{Evaluation of kidney transplant recipient and donor}

Thorough assessment of all the donors and recipients is very important aiming to ensure donor safety and graft outcome. ${ }^{37}$ This is done using specific standard methods. These include blood and urine screening tests, chest x-ray, electrocardiogram, an age- and family history-appropriate cardiac stress test. Radiological assessment includes computed tomography (CT), renal arteriogram, and magnetic resonance angiography. The $\mathrm{CT}$ angiogram has been shown to be reliably accurate. ${ }^{38}$.An outline of the evaluations performed for both the donors and recipients are shown in Tables $2 \& 3 .{ }^{6}$ Living donation creates a conflict between the duty to do no harm and the duty to respect the donor's autonomy. ${ }^{39}$ An informed consent is a fundamental step of the donor evaluation. It includes a careful assessment of the donor's capacity to understand the provided information and to make decisions.

Table 2 Living donor evaluation checklist

\begin{tabular}{l} 
Living Donor Evaluation \\
\hline History \\
Hypertension \\
Diabetes (including gestational) \\
Infections \\
Cancer \\
Vascular disease \\
Renal calculi \\
Gout \\
Urinary tract \\
Family history \\
Medications \\
Smoking \\
Illicit and intravenous drug use \\
Sexual history \\
Vocation, sport interests \\
Level of physical activity, exercise \\
Psychiatric history, psychological factors \\
Willingness to donate \\
Relationship with recipient \\
Examination \\
Blood pressure \\
Weight and height, BMI \\
Joints, skin
\end{tabular}

Cancer (including skin lesions, breast)

Lymph nodes

Vascular disease

Heart and lungs

Abdomen

Laboratory and Radiologic Investigations

Urinalysis (blood, protein)

Urine microscopy and culture (blood, organisms)

Serum electrolytes, urea, and creatinine

Liver function tests

Full blood examination

Fasting blood glucose and/or oral glucose tolerance test

Fasting lipids

24-hour urine, creatinine clearance or GFR measurement by iothalamate,

Cr-EDTA, DTPA clearance, 24-hour urine protein, or protein excretion

by other methods (e.g., protein-creatinine ratio)

Serum uric acid, calcium, phosphate

Viral screening: HBV, HCV, HIV, CMV, EBV serology

Syphilis screening (RPR)

TB screening (PPD)

Electrocardiogram

Chest radiograph

Females: Pap smear, mammography (according to age and family history)

Males: prostate-specific antigen (according to age and family history)

Additional cardiac investigations

Stress test

Echocardiography

Ambulatory blood pressure

Renal Imaging

Computed tomographic angiography

Magnetic resonance imaging angiography

Catheter angiography

BMI, body mass index; CMV, cytomegalovirus; Cr-EDTA, chromium-labeled ethylenediaminetetraacetic Acid; DTPA, diethylenetriaminepentaacetic acid; EBV, epstein-barr virus; GFR, glomerular filtration rate; HBV, hepatitis B virus; HCV, hepatitis C virus; HIV, human immunodeficiency virus; PPD, purified protein derivative test; RPR, rapid plasmin reagent;TB, tuberculosis

Table 3 Recipient evaluation checklist

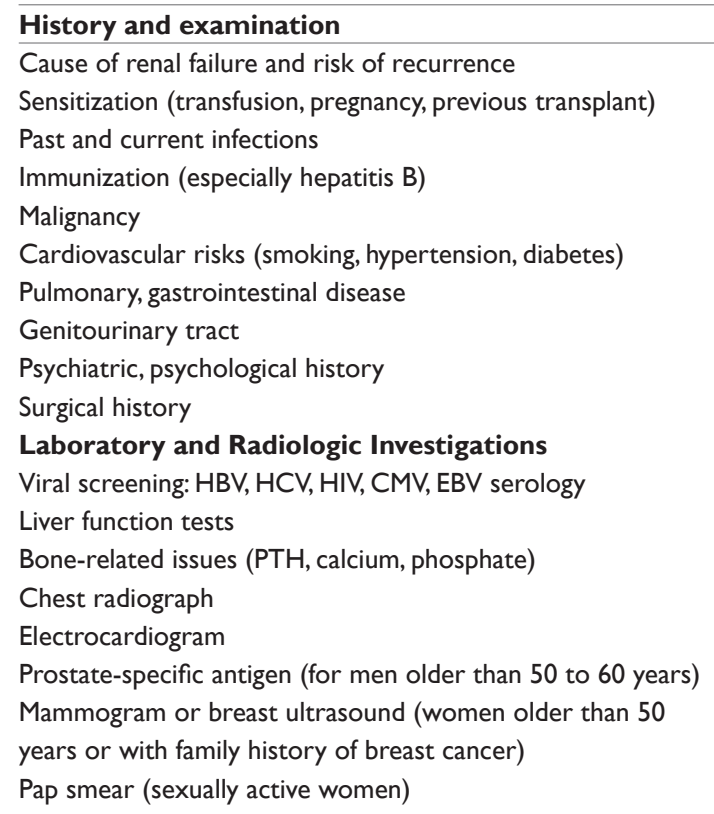


Table Continued...

\section{Immunologic Investigations}

ABO blood group and HLA typing

Screening for HLA antibodies and autoreactive antibodies

Crossmatching

HLA, human leukocyte antigen; PTH, parathyroid hormone

The donor must be informed with all details about the different elements of the donor evaluation process, surgical procedure, recovery period, potential medical or psychosocial risks, follow-up requirements (long and short term), quality of life after donation, availability of alternative treatments for the recipient, the recipient's risks, recurrent disease, chances for survival (national and centerspecific), outcomes for recipients and living donors. In addition, the donor must be informed about the possibility that medical evaluation could reveal conditions that must be reported to the governmental authorities, such as human immunodeficiency virus infection. Also, the possibility that future health problems related to the donation may not be covered by the donor's insurance is another important information that needs to be clarified to the donor especially with the ability to obtain health disability. The donor must know that he has the right to opt out of donation at any time. ${ }^{40}$

The economic impact of donation should be discussed with the prospective donor. The act of donation should not preclude the donor from obtaining medical insurance or increase the cost of insurance. ${ }^{41}$ In the USA, the organ donor leave act was created in 1999 and entitles the donor for 30 days of paid leave. However, it is recommended that the prospective donor obtain health and life insurance prior to donation. The donor should be financially stable and free of financial hardship. The evaluation should explore the ability of the donor to cover financial obligations for expected and unexpected donation-related expenses. The donor should be able to afford time away from work mainly for unplanned extended recovery time..$^{42}$ Renal transplantation in elderly patients with end stage kidney disease follows the same previous work up with more meticulous screen for cardiovascular disease and cancer. Significant age-related comorbidities could be considered as relative contraindications to renal transplantation. However, the specific investigation methods and time intervals to be used, as well as criteria for exclusion, are still poorly defined and not supported by evidence. ${ }^{43}$

For cardiac evaluation, noninvasive stress testing may be considered in asymptomatic patients 60years or older who also have at least 2 other risk factors for coronary artery disease, although there is little evidence to support this recommendation. ${ }^{44}$.With regard to malignancy, age-appropriate screening as indicated for the general population should be performed for renal transplantation candidates, in the absence of specific guidelines for these patients. This usually includes colonoscopy in patients 50years or older and mammogram in women 40years or older. ${ }^{45}$ In summary, renal transplantation appears to be safe in the elderly, if candidates are carefully selected. Given the senescence of the immune system, the use of lower doses of immunosuppressive drugs is likely to minimize side effects, without excess rejections; however, specific options need to be tested in randomized controlled trials. Death-censored graft survival is similar or even better in elderly recipients, as compared with younger counterparts. ${ }^{43}$

\section{Immunosuppressive agents}

There is a continuous progress in immunosuppressive therapy with the development of new drugs and combinations. At the start, there was the standard protocol of prednisone, azathioprine, and
Cyclosporine (CsA). Currently, there are several combinations of FDA-approved medications, which allow each center to select the best immunosuppressive protocol to adopt for transplant recipients. These include tacrolimus, mycophenolate mofetil (MMF), and sirolimus, and as well induction therapy as anti lymphocyte preparations, basiliximab and alemtuzumab. The improvements in short-term kidney graft survival are in large part due to these agents. Improvement in long term graft survival associated with these newer medications has been more difficult to prove, mostly due to lack of statistical power in prospective trials. Optimizing graft survival following kidney transplantation is an ongoing challenge. Induction therapy can reduce the incidence of acute rejection, but questions remain which is the safest and most effective approach. ${ }^{46}$ A successful kidney transplant markedly improves the quality of life and reduces complications and mortality. Those patients are maintained on immunosuppressive medications that increase the risk of complications such as cardiovascular disease, infection, malignancy. Therefore, renal allograft recipients require close follow-up after transplantation. This includes thorough clinical assessment, laboratory investigations and radiological investigations. The frequency of the follow up visit varies according to the time posttransplant. ${ }^{47}$

\section{Factors affecting graft survival}

Patient and graft survival after kidney transplantation showed significant improvement over the pastdecade. Data from the Scientific Registry of Transplant Recipients (SRTR) reported a10-year overall graft survival of55 to $60 \%$ for both living and deceased donors. ${ }^{9}$ Despite the significant improvements in one year graft survival, the rate of chronic graft loss after the first year remains substantial. ${ }^{48}$ In a study by Meier-Kriesche and colleagues, first renal transplants performed in the period between 1995 and 2000 were analyzed. The authors concluded that, despite a reduction in acute rejection rates, there was no improvement in allograft survival over this interval. ${ }^{49}$ As an example, any short-term event that predisposes to episodes of acute rejection will then lead to a greater likelihood of chronic graft loss. In addition, many of these factors influence each other, such as human leukocyte antigen (HLA) mismatching, which may increase the risk of acute renal rejection and subsequent premature allograft failure.

\section{Factors affecting short-term survival}

A number of factors have been shown to influence short-term renal allograft survival. These include delayed allograft function (DGF), type of donor kidney, dialysis or preemptive transplantation, immunologic factors, donor age and other factors. ${ }^{50}$ The major improvement in renal allograft survival achieved in the past 20 years was due to relative elimination of the early-risk period.

\section{Delayed allograft function}

The presence of delayed graft function (DGF) has a major adverse impact upon both short and long-term allograft survivals. In a singlecenter study, multivariate analysis of 518 renal transplant recipients found that DGF was the principal factor underlying kidney survival at one year. ${ }^{51}$

\section{Type of donor kidney}

Living transplants have a $15 \%$ greater one-year graft survival rate than cadaver kidneys. A graft survival benefit with living transplants is also observed with second allograft. This difference reflects the optimal circumstances surrounding living-related donation compared with the potentially injurious effect of cadaveric donation. ${ }^{52}$ 


\section{Preemptive transplantation}

Allograft survival may vary with the use of pretransplant maintenance dialysis and perhaps the type of dialysis. In a retrospective study of over 8000 patients, preemptive transplantation of a living donor kidney was associated with a $52 \%$ and $82 \%$ lower risk of allograft failure at one and two years after transplantation, respectively, compared to that for patients maintained on dialysis. The underlying mechanism of this benefit is unclear, but may be related to an enhanced immunologic effect with dialysis. ${ }^{21}$ In addition, the prior use of peritoneal dialysis was associated with a $23 \%$ higher risk of allograft failure during the first three months post-transplant versus that observed with hemodialysis. ${ }^{53}$ The adverse effect of dialysis is duration-dependent. Meier-Kriesche and Kaplan reported that transplant outcomes were worse in paired recipients from the same donor who had been dialyzed for more than 24 months compared to less than six months. Ten year overall adjusted graft survival was significantly lower with prolonged dialysis for both cadaveric (39 vs. $69 \%$ ) and living donor transplants (49 vs. $75 \%) .{ }^{20}$.

\section{Immunologic factors}

Increases sensitization to lymphocyte antigens as measured by the panel reactive antibody (PRA) especially donor specific status augments the risk of graft loss incrementally. HLA mismatching also significantly influences short and long term graft survival..$^{50}$

\section{Donor age}

Donor age has an impact on graft survival. Increasing donor age was found to be associated with inferior survival of allografts from deceased donors. In an analysis of 6490 deceased-donor kidney transplants identified from the UK transplant registry, donor age more than 60 years was associated with higher risk of graft failure when compared with donors less than 40years old..$^{54,55}$

\section{Center effect}

This is present in USA, Canada and Europe and cannot be explained by any clinical features of patients. This may be related to differences inexperience with long-term patient management. ${ }^{56}$

\section{Factors affecting long-term survival}

Several studies were conducted to identify the clinical risk factors for long-term allograft failure. ${ }^{57,58}$ Chronic allograft dysfunction (CAN) which is still the main cause of late allograft loss. However, the exact mechanisms for the development of CAN are unknown. Both alloantigen dependent and independent factors are thought to play a role.

\section{Alloantigen-dependent factors}

These include HLA mismatch, sensitization and history of acute rejection episodes. ${ }^{22}$ In a Minnesota study, chronic rejection was reported to complicate acute rejection episodes in $20 \%$ of living and $36 \%$ of cadaver donor recipients. On the other hand, patients with no history of rejection had less than a $1 \%$ chance of eventually developing chronic disease. ${ }^{59}$ Sensitization caused by antibodies against HLA class I or class II is found in subjects who have been immunized to these glycol proteins by pregnancy, blood transfusion, or a prior HLA mismatched allograft. The presence of HLA antibodies is associated with an increased risk of graft loss. ${ }^{60}$ The incidence of antibody mediated rejection was nine fold higher in those with preformed donor specific antibodies (DSA) ${ }^{61}$

\section{Alloantigen-independent factors}

Many alloantigen independent factors play an important role in late allograft loss. Some of these factors include living kidney donors, tissue injury, inadequate renal mass, drug noncompliance, drug calcineurin inhibitor (CNI) toxicity, hypertension, recurrent or de novo glomerular disease and Infection (CMV, BK Nephropathy). Living donor transplants have better long-term allograft survival rate than cadaveric. A graft survival benefit with living transplants is also observed with second allograft. ${ }^{52}$ There is increasing realization that allograft injury caused by ischemia and/or reperfusion injury may play a major role in both short- and long-term graft functions, as well as in the induction of renal allograft rejection. ${ }^{62}$

Transplantation of inadequate renal mass may be associated with a higher risk of renal graft failure. In a large study, the low weight of the kidney relative to the weight of the recipient $(\mathrm{Kw} / \mathrm{Rw})$ (less than $2.3 \mathrm{~g} / \mathrm{kg}$ ) was associated with an increased risk of glomerulosclerosis (17 vs. $4.7 \%$ ), proteinuria, and long-term allograft loss (1.55 fold increased risk.1.01: $2.12,95 \% \mathrm{CI}$ beginning two years post-surgery). The magnitude of risk for decreased allograft survival of a low Kw/ $\mathrm{Rw}$ is approximately the same as the risk due to an acute rejection episode or delayed allograft function. ${ }^{63}$

Drug noncompliance is one of the most important risk factors for renal graft loss. In a single center series, noncompliance was responsible for allograft loss in at least 11 and $13 \%$ of living donor and cadaveric allograft respectively ${ }^{64}$ Calcineurin Inhibitor (CNI) nephrotoxicity has been described to be 'universally' present at 10 years, even in grafts with excellent function. It was incriminated in the lack of improvement in long-term kidney allograft survival. Over the last three decades, chronic CNI toxicity contributes to late allograft loss. It was found to be the major cause of chronic renal allograft damage and characterized byinterstitial fibrosis, tubular atrophy, arteriolar hyalinosis, and glomerulosclerosis. ${ }^{65}$

Long-term patient and allograft survival may be negatively influenced by the development of post-transplant hypertension. ${ }^{66}$ Control of blood pressure is an important factor that can improve graft outcome. The goal blood pressure is $140 / 90 \mathrm{mmHg}$ in patients without diabetes or proteinuria, and $130 / 80 \mathrm{mmHg}$ in those with diabetes or proteinuria ${ }^{67}$ In addition, some antihypertensive therapy may have a beneficial nephroprotective effect that can improve graft survival. In an animal model of chronic renal allograft rejection, it was associated with diminished glomerular injury, and reduced proteinuria. ${ }^{68}$ Recurrent or de novo glomerular disease results in significantly lower long-term allograft survival. ${ }^{69,70}$

\section{Policies to enhance living donation}

It was found that more than $50 \%$ of potential living donors who are suitable for donation failed to proceed. This was found to be due to circulating donor-specific antibodies (ABO or HLA) on immunologic screening of the recipient. ${ }^{71}$ Medical professionals and governments have realized this fact and have undertaken different approaches to increase transplantation rates through living donation. ${ }^{72,73}$ A survey of the membership of the American Society of Transplant Surgeons revealed that most members support payment for lost wages, guaranteed health insurance and an income tax credit as strategies to increase living donation. ${ }^{74}$ Additionally, public meetings were held by non-transplant centers, such as organ procurement organizations (OPOs) to explain the need for living donors and to prescreen potential living donors before referral to a transplant center. This helped to expedite the process from identification of a potential donor to actual donation. ${ }^{75}$ 
It appears that focusing a transplant center's mission on living donation may increase the number of living donors. Several transplant centers have improved the growth and effectiveness of living donor programs. This was done through encouraging the practice of having recipients present to evaluation appointments with friends and family thus extending the awareness of the issues involved in transplantation to more and more people. Also, the introduction of the concept of paired organ exchange or non-directed organ donation to an exchange list has markedly increased the number of living donor transplants. However, to encourage donor exchange in some nations, the potential participant donor cultures must be assimilated into the country's general culture and conventional thought. ${ }^{72}$

Education becomes critical, many do not know the facts about the risks and long-term outcomes of living donation, and thus are afraid to engage others in a conversation that would lead to individuals considering living donation. Patients in need of transplants need to be educated to understand the short- and long-term outcomes and the care available to living donors. Potential recipients should not feel guilty about living donation. ${ }^{76,77}$ Other approaches such as advances in surgical techniques can encourage and improve living donation concept. The development of laparoscopic nephrectomy was a tremendous advance because it decreased disfigurement and reduced pain and time to recovery. ${ }^{78}$

Global Kidney Exchange (GKE) is a novel approach that helps international and US pairs to overcome both ABO/HLA incompatibility as well as financial barriers to transplantation. The foundation of GKE is built upon three premises. First, ESRD patients in developing countries are often prohibited from undergoing transplantation due to inadequate national government support of transplantation/immunosuppression or personal financial limitations despite access to willing emotionally related living donors. Second, KPD participation in the USA is confined almost exclusively to incompatible donor/recipient pairs with immunological barriers to transplantation. Third, health insurance providers pay significantly more for the provision of dialysis over time as compared with cost of renal transplantation over the same time period in the developed world. ${ }^{79}$ In the USA, commercial insurance payers are obligated to pay for the cost of ESRD treatment for the first 33 months following diagnosis, after which time the Medicare ESRD program becomes the primary payer. During this 33-month time frame, the cost of dialysis is three times the cost of preemptive kidney transplantation and subsequent immunosuppression. ${ }^{80,81}$

Thus, both private and government payers are financially benefited by expedient transplantation. Furthermore, payers could finance the cost of two kidney transplants and subsequent immunosuppression and still save as much as one third the total cost of dialysis. The cost/ benefit ratio diminishes for private payers as the 33 months progress, but remains unchanged for Medicare beneficiaries. GKE allows for a redistribution of current ESRD treatment resources such that lowincome populations are provided developed-world healthcare. The redistribution of resources enacted by GKE changes the allocation of healthcare spending to benefit both rich and poor. ${ }^{79}$ GKE is a promising program that can expand KPD and renal transplantation as a whole.

\section{Conclusion}

The wide gap between kidney supply and demand resulted in long waiting times on maintenance dialysis with high morbidity and mortality. Living donation is one of the important solutions for this problem. A lot of effort is required to enhance the living donation.

\section{Conflicts of interest}

The authors declare that there are no conflicts of interest regarding the publication of this paper.

\section{Acknowledgements}

I want to thank all the authors for their valuable effort in this manuscript.

\section{Ethical approval}

The study was approved by our ethics committee.

\section{Funding}

None.

\section{References}

1. Yoo SW, Kwon OJ, Kang CM. Preemptive living-donor renal transplantation outcome and clinical advantages. Transplant Proc. 2009;41(1):117-120

2. Horvat LD, Shariff SZ, Garg AX. Global trends in the rates of living kidney donation. Kidney Int. 2009;75(10):1088-1098.

3. Miles CD, Schaubel DE, Liu D, et al. The role of donor recipient relationship in long-term outcomes of living donor renal transplantation. Transplantation. 2008;85(10):1483.

4. Lytton B. The early history of kidney transplantation at Yale (19671985):A personal memoir. Yale J Biol Med. 2005;78(3):173-184.

5. Murray JE. The first successful organ transplants in man. $J$ Am Coll Surg. 2005;200(1):5-9.

6. Johnson RJ, Feehally J, Floege. Comprehensive clinical nephrology. 5th edn. Philadelphia, Saunders: Elsevier Inc. 2005.

7. EBPG (European Expert Group on Renal Transplantation); European Renal Association (ERA-EDTA); European Society for Organ Transplantation (ESOT) (2000) European Best Practice Guidelines for Renal Transplantation (Part 1). Nephrol Dial Transplant. 2000;15(Suppl 7): $1-85$.

8. Knoll G, Cockfield S, Blydt-Hansen T, et al. Canadian Society of Transplantation:Consensus guidelines on eligibility for kidney transplantation. CMAJ. 2005;173(10):S1-S25.

9. Hart A, Smith JM, Skeans MA, et al. OPTN/SRTR 2015 annual data report: Kidney. Am J Transplant. 2017;17(S1):21-116.

10. Delmonic FL, Sheehy E, Marks WH, et al. Organ donation and utilization in the United States, Am J Transplant. 2005;5((4 Pt 2):862-873.

11. Cecka JM (2003) The OPTN/UNOS Renal Transplant Registry. Clin Transpl. 2003;1-12.

12. Gjertson DW (2003) Look-up survival tables for living-donor renal transplants: OPTN/UNOS data 1995-2002. Clin Transpl. 2003;337386.

13. Danovitch G. Medical and surgical aspects of kidney donation. 4th edn USA: Lippincott Williams \& Wilkins; 2005.

14. Cohen EP, Rosendale JD, Bong CJ, et al. Benefit of child-to-parent kidney donation. Am J Transplant. 2003;3(7):865-872.

15. Delmonico FL, Dew MA. Living donor kidney transplantation in a global environment. Kidney Int. 2007;71(7):608-614.

16. Wallis CB, Samy KP, Roth AE, et al. Kidney paired donation. Nephrol Dial Transplant. 2011;26(7):2091-2099. 
17. Glorie K, Haase-Kromwijk B, van de Klundert J, et al. Allocation and matching in kidney exchange programs. Transpl Int. 2014;27(4):333343.

18. De Klerk M, Keizer K, Claas F, et al. The Dutch national living donor kidney exchange program. Am J Transplant. 2005;5(9):2302-2305.

19. Böhmig GA, Fronek J, Slavcev A, et al. Czech-Austrian kidney paired donation: first European cross-border living donor kidney exchange. Transpl Int. 2017;30(6):638-639.

20. Meier-Kriesche HU, Kaplan B. Waiting time on dialysis as the strongest modifiable risk factor for renal transplant outcomes: A paired donor kidney analysis. Transplantation. 2002;74(10):1377-1381.

21. Mange KC, Joffe MM, Feldman HI. Effect of the use or nonuse of longterm dialysis on the subsequent survival of renal transplants from living donors. N Engl J Med. 2001;344(10):726-731.

22. Collins AJ, Foley R, Herzog C, et al. Excerpts from the United States renal data system 2007 annual data report. Am J Kidney Dis. 2008;51(1 Suppl 1):S1-S320.

23. Najarian JS, Gillingham KJ, Sutherland DER, et al. The impact of the quality of initial graft function on cadaver kidney transplants. Transplantation. 1994;57(6):812-816.

24. Terasaki PI, Cecka JM, Gjertson DW, et al. High survival rates of kidney transplants from spousal and living unrelated donors. $N$ Engl J Med. 1995;333(6):333-336.

25. Donnelly PK, Oman P, Henderson R, et al. Predialysis living donor renal transplantation: Is it still the "gold standard" for cost, convenience and graft survival? Transplant Proc. 1995;27(1):1444-1446.

26. Frazier PA, Davis-Ali SH, Dahl KE. Correlates of noncompliance among renal transplant recipients. Clin Transplant. 1994;8(6):550-557.

27. Delmonico F. A report of the Amsterdam forum on the care of the live kidney donor: Data and medical guidelines. Transplantation. 2005;79(6 Suppl):S53-S66.

28. Muzaale AD, Massie AB, Wang MC, et al. Risk of end-stage renal disease following live kidney donation. JAMA. 2014;311(6):579-586.

29. Ibrahim HN, Foley R, Tan L, et al. Long-term consequences of kidney donation. N Engl J Med. 2009;360(5):459-469.

30. Cherikh WS, Young CJ, Kramer BF, et al. Ethnic and gender related differences in the risk of end-stage renal disease after living kidney donation. Am J Transplant. 2011;11(8):1650-1655.

31. Hesselink DA, Weimar W. Renal transplantation in 2014:renal transplantation-reducing risk and improving outcome. Nat Rev Nephrol. 2015;11(2):72-73.

32. Kasiske BL, Ravenscraft M, Ramos EL, et al. The evaluation of living renal transplant donors:clinical practice guidelines. Ad Hoc Clinical Practice Guidelines Subcommittee of the Patient Care and Education Committee of the American Society of Transplant Physicians. J Am Soc Nephrol. 1996;7(11):2288-2313.

33. Screening of donor and recipient prior to solid organ transplantation. Am J Transplant. 2004;4 (Suppl 10):10-20.

34. McKay DB, Milford EL, Sayegh MH. Clinical aspects of renal transplantation. In: The Kidney. 5th edn. In: Brenner BM, REctor FC, Editors. Philadelphia, USA: Saunders; 2000.

35. Naik RP, Derebail VK, Grams ME, et al. Association of sickle cell trait with chronic kidney disease and albuminuria in African Americans. JAMA. 2014;312(20):2115-2125.

36. Mandelbrot DA, Pavlakis M, Danovitch GM, et al. The medical evaluation of living kidney donors:a survey of US transplant centers. Am J Transplant. 2007;7(10):2333.

37. Ethics Committee of the Transplantation Society. The consensus statement of the Amsterdam Forum on the care of the live kidney donor. Transplantation. 2004;78(4):491-492.

38. Kapoor A, Kapoor A, Majajan G, et al. Multispiral computed tomographic angiography of renal arteries of live potential renal donors: A review of 118 cases. Transplantation. 2004;77(10):1535-1539.

39. Petrini C. Ethical issues with informed consent from potential living kidney donors. Transplant Proc. 2010;42(4):1040-1042.

40. Rudow DL. The living donor advocate:A team approach to educate, evaluate, and manage donors across the continuum. Prog Transplant. 2009;19(1):64-70

41. Pham PC, Wilkinson AH, Pham PT. Evaluation of the potential living kidney donor. Am J Kidney Dis. 2007;50(6):1043-1051.

42. Dew MA, Jacobs CL, Jowsey SG, et al. Guidelines for the psychosocial evaluation of living unrelated kidney donors in the United States. Am J Transplant. 2007;7(5):1047-1054.

43. Segall L, Nistor I, Pascual J, et al. Criteria for and Appropriateness of Renal Transplantation in Elderly Patients With End-Stage Renal Disease:A Literature Review and Position Statement on Behalf of the European Renal Association-European Dialysis and Transplant Association Descartes Working Group and European Renal Best Practice. Transplantation. 2016;100(10):e55-e65.

44. Lentine KL, Costa SP, Weir MR, et al. Cardiac disease evaluation and management among kidney and liver transplantation candidates: a scientific statement from the American Heart Association and the American College of Cardiology Foundation. $\mathrm{J}$ Am Coll Cardiol. 2016;60(5):434-480.

45. Bunnapradist S, Danovitch GM. Evaluation of adult kidney transplant candidates. Am J Kidney Dis. 2007;50(5):890-898.

46. Morgan RD, O'Callaghan JM, Knight SR, et al. Alemtuzumab induction therapy in kidney transplantation: a systematic review and metaanalysis. Transplantation. 2012;93(12):1179-1188.

47. Schnuelle $\mathrm{P}$, Lorenz $\mathrm{D}$, Trede $\mathrm{M}$, et al. Impact of renal cadaveric transplantation on survival in end-stage renal failure:evidence for reduced mortality risk compared with hemodialysis during long-term follow-up. J Am Soc Nephrol. 1998;9(11):2135-2141.

48. Hariharan S, Johnson CP, Bresnahan BA, et al. Improved graft survival after renal transplantation in the United States, 1988 to 1996. N Engl J Med. 2000;342(9):605-612.

49. Meier-Kriesche HU, Schold JD, Srinivas TR, et al. Lack of improvement in renal allograft survival despite a marked decrease in acute rejection rates over the most recent era. Am J Transplant. 2004;4(3):378.

50. Prommool S, Jhangri GS, Cockfield SM, et al. Time dependency of factors affecting renal allograft survival. $J$ Am Soc Nephrol. 2000;11(3):565-573.

51. Quiroga I, McShane P, Koo DD, et al. Major effects of delayed graft function and cold ischaemia time on renal allograft survival. Nephrol Dial Transplant. 2006;21(6):1689-1696.

52. Port FK, Dykstra DM, Merion RM, et al. Trends and results for organ donation and transplantation in the United States, 2004. Am J Transplant. 2005;5(4 Pt 2):843-849.

53. Snyder JJ, Kasiske BL, Gilbertson DT, et al. A comparison of transplant outcomes in peritoneal and hemodialysis patients. Kidney Int. 2002;62(4):1423-1430.

54. Summers DM, Johnson RJ, Hudson A, et al. Effect of donor age and cold storage time on outcome in recipients of kidneys donated after circulatory death in the UK:a cohort study. Lancet. 2013;381(9868):727-734.

55. Watson CJ, Johnson RJ, Birch R, et al. A simplified donor risk index for predicting outcome after deceased donor kidney transplantation. Transplantation. 2012;93(3):314-318. 
56. Kim SJ, Schaubel DE, Jeffery JR, et al. Centre-specific variation in renal transplant Outcomes in Canada. Nephrol Dial Transplant. 2004;19(7):1856-1861.

57. Fellström B, Holdaas H, Jardine AG, et al. Risk factors for reaching renal endpoints in the assessment of Lescol in renal transplantation (ALERT) trial. Transplantation. 2005;79(2):205-212.

58. He X, Johnston A. Risk factors for allograft failure in United kingdom renal transplant recipients treated with cyclosporine A. Transplantation. 2005;79(8):953-957.

59. Basadonna GP, Matas AJ, Gillingham KJ, et al. Early versus late acute renal allograft rejection:Impact on chronic rejection. Transplantation. 1993;55(5):993-995.

60. Terasaki PI, Ozawa M. Predicting kidney graft failure by HLA antibodies:A prospective trial. Am J Transplant. 2004;4(3):438-443.

61. Lefaucheur C, Suberbielle-Boissel C, Hill GS, et al. Clinical relevance of preformed HLA donor-specific antibodies in kidney transplantation. Am J Transplant. 2008;8(2):324-331.

62. Lu CY, Penfield JG, Kielar ML, et al. al. Hypothesis: Is renal allograft rejection initiated by the response to injury sustained during the transplant process? Kidney Int. 1999;55(6):2157-2168.

63. Giral M, Foucher Y, Karam G, et al. Kidney and recipient weight incompatibility reduces long-term graft survival. J Am Soc Nephrol. 2010;21(6):1022.

64. Butler JA, Roderick P, Mullee M, et al. Frequency and impact of nonadherence to immunosuppressants after renal transplantation:a systematic review. Transplantation. 2004;77(5):769-776.

65. Nankivell BJ, Borrows RJ, Fung CL, et al. The natural history of chronic allograft nephropathy. N Engl J Med. 2003;349(24):2326-2333.

66. Kasiske BL, Anjum S, Shah R, et al. Hypertension after kidney transplantation. Am J Kidney Dis. 2004;43(6):1071-1081.

67. Ruzicka M, Quinn RR, McFarlane P, et al. Canadian Society of Nephrology commentary on the 2012 KDIGO clinical practice guideline for the management of blood pressure in CKD. Am J Kidney Dis. 2014;63(6):869-887.

68. Paul LC, Benediktsson H. Post-transplant hypertension and chronic renal allograft failure. Kidney Int Suppl. 1995;52:S34-S37.
69. Hariharan S, Adams MB, Brennan DC, et al. Recurrent and de novo glomerular disease after renal transplantation:a report from Renal Allograft Disease Registry (RADR). Transplantation. 1999;68(5):635641.

70. Briganti EM, Russ GR, McNeil JJ, et al. Risk of renal allograft loss from recurrent glomerulonephritis. N Engl J Med 2002;347(2):103-109.

71. Karpinski M, Knoll G, Cohn A, et al. The impact of accepting living kidney donors with mild hypertension or proteinuria on transplantation rates. Am J Kidney Dis. 2006;47(2):317-323.

72. Roodnat JI, van de Wetering J, Zuidema W, et al. Ethnically diverse populations and their participation in living kidney donation programs. Transplantation. 2010;89(10):1263-1269.

73. Baines LS, Joseph JT, Jindal RM. A public forum to promote organ donation amongst Asians:the Scottish initiative. Transplant. 2002;15(23):124-131.

74. Rodrigue JR, Crist K, Roberts JP, et al. Stimulus for organ donation:a survey of the American Society of Transplant Surgeons membership. Am J Transplant. 2009;9(9):2172-2176.

75. Mark PJ, Baker K, Aguayo C, et al. Experience with an organ procurement organization-based non-directed living kidney donation programme. Clin Transplant. 2006;20(4):427-437.

76. Barnieh L, McLaughlin K, Manns B, et al. Development of a survey to identify barriers to living donation in kidney transplant candidates. Prog Transplant. 2009;19(4):304-311.

77. Young A, Karpinski M, Treleaven D, et al. Differences in tolerance for health risk to the living donor among potential donors, recipients, and transplant professionals. Kidney Int. 2008;73(10):1159-1166.

78. Nicholson ML, Kaushik M, Lewis GR, et al. Randomized clinical trial of laparoscopic versus open donor nephrectomy. Br J Surg. 2010;97(1):2128.

79. Robert Brunner, David Fumo, Michael Rees. Novel Approaches to Expanding Benefits from Living Kidney Donor Chains. Curr Transpl Rep. 2017;4(2):67-74.

80. Held PJ, McCormick F, Ojo A, et al. A cost-benefit analysis of government compensation of kidney donors. Am J Transplant 2016;16(3):877-885.

81. Irwin FD, Bonagura AF, Crawford SW, et al. Kidney paired donation:a payer perspective. Am J Transplant. 2012;12(6):1388-1391. 